\title{
Relationship between self-reported bruxism and torus mandibularis of patients with temporomandibular disorders
}

\author{
Chan-Young Cheon ${ }^{1}$, A-Hyang Yoon ${ }^{2}$, Jong-Mo Ahn ${ }^{2,3, *}$ \\ ${ }^{1}$ Department of Dentistry, Graduate School, Chosun University, Gwangju, Korea \\ ${ }^{2}$ Department of Oral Medicine, School of Dentistry, Chosun University, Gwangju, Korea \\ ${ }^{3}$ Oral Biology Research Institute, Chosun University, Gwangju, Korea
}

The objective of the study was to evaluate the relationship between self-reported bruxism and torus mandibularis in patients with temporomandibular disorders (TMD). The subjects of the study were 375 patients diagnosed with TMD and 433 control patients at Chosun University Dental Hospital from November 1, 2017 to June 30, 2018. Self-reported bruxism and torus mandibularis in each group were investigated and compared statistically. Female in sex distribution and prevalence of self-reported bruxism and torus mandibularis was more common in TMD group than in control group $(p<0.05)$. Bruxism and torus mandibularis might be useful as indicators of increased risk of TMD.

Key Words: Self-reported bruxism, Temporomandibuar disorders, Torus mandibularis

(a) This is an open-access article distributed under the terms of the Creative Commons Attribution Non-Commercial License (http://creativecommons.org/licenses/by-nc/4.0) which permits unrestricted noncommercial use, distribution, and reproduction in any medium, provided the original work is properly cited.

\section{서 론}

측두하악장애(temporomandibular disorders, TMD)는 구 강악안면 영역에서 발생하는 근골격계 질환으로 비치성통증 (nondental pain)의 주요 원인으로 알려져 있다. 임상증상으로 는 측두하악관절(temporomandibular joint)과 저작근의 통증, 관절잡음(clicking sound), 개구 제한(mounth opening limitation), 귀의 통증, 두통 등이 주로 나타난다[1,2].

원인은 복합적이고 다양한데, 교합상태, 외상, 정서적 스트레 스, 심부통증 유입, 이상기능 활동(parafunctional activity) 등 이 주요 원인으로 알려져 있다[3]. TMD의 많은 원인들 중에서 이갈이(bruxism)는 정서적 스트레스 및 이상기능 활동과 관련 되어 병력검사에서 흔하게 발견된다. 이갈이는 주간 활동(diur- nal activity)과 야간 활동(noctunal activity)을 하는 동안 이악 물기(clenching)와 같은 단일성 수축이나 이갈이(bruxing)와 같은 율동적인 수축의 형태로 나타나며, 저작근육의 과활성을 나타낸다[2,4].

하악골융기(torus mandibularis)는 자연적으로 발생하는 외 골증(exostosis)으로, 주로 소구치 부위 악설골융선(mylohyoid ridge) 위에 나타난다[5,6]. 원인은 아직까지 명확하지 않지만, 진화(evolution), 유전적 요소, 과도한 저작기능(masticatory hyperfunction) 등이 원인으로 고려되고 있고[7], 다른 연구자들 은 과도한 교합력이 외골증의 성장을 자극한다고 믿고 있다[8].

따라서 이갈이와 같은 이상기능 활동이 하악골융기와 $\mathrm{TMD}$ 의 원인과 관련된다면, TMD 환자에서 하악골융기는 더 많은 유 병률을 나타나게 될 것이다. 또한 TMD 임상검사를 시행할 때

Received February 28, 2019; Revised June 26, 2019; Accepted June 26, 2019

Corresponding author: Jong-Mo Ahn, Department of Oral Medicine, School of Dentistry, Chosun University, 309 Pilmun-daero, Dong-gu, Gwangju 61452, Korea.

Tel: +82-62-220-3890, Fax: +82-62-234-2119, E-mail: jmahn@chosun.ac.kr

Copyright $\odot$ 2019, Oral Biology Research Institute 
검사항목에 하악골융기의 존재를 포함시켜야 할 수도 있다.

이에 본 연구는 TMD 환자에서 이갈이와 하악골융기의 유병 률을 조사하여 서로 연관성이 있는지 알아보고자 한다.

\section{대상 및 방법}

\section{연구대상}

2017년 11월 1일부터 2018년 6월 30일까지 조선대학교 치 과병원에 내원한 TMD로 진단된 환자 375명(남자 153명, 여 자 222명)과 $\mathrm{TMD}$ 의 병력이 없는 환자 433명(남자 223명, 여 자 210명)을 대상으로 하였다. 이 연구는 조선대학교 치과 병원 임상윤리심의위원회의 승인을 받아 진행하였다(CUDHIRB-01805-001).

\section{연구방법}

모든 환자들은 치료 전에 병력검사를 시행하였으며, 나이와 성별을 조사하였다. 임상검사에서 하악골융기와 이갈이 존재 여부를 파악하였으며, 이갈이는 본인이 인지하고 있는 낮과 밤 에 이악물기나 이갈이와 같은 비기능적 습관(parafunctional habits)이 존재하는지 여부와 같이 잠을 자는 사람(sleep partner)이나 주변 다른 사람들에 의해 자는 동안 이갈이 여부에 대 한 습득된 정보를 통해 자가 보고하도록 하였다. 하악골융기는 하악 제 1,2 소구치 설측부위에 시진과 촉진을 통해 골의 융기 가 존재하는지 여부를 조사하였다(Fig. 1). 하악골융기의 크기, 개수와 좌, 우측 존재유무는 따로 분류하지 않았다.

\section{통계분석}

이 연구에서 사용된 통계 분석은 SPSS (version 18.0; SPSS Inc., Chicago, IL, USA)를 이용하였다. TMD 환자군과 대조군

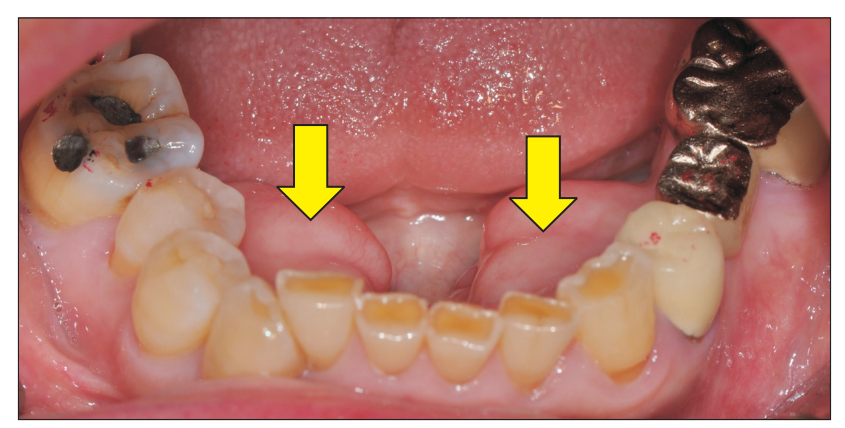

Fig. 1. Tori mandibularis (arrows).
으로 분류하여 환자의 성별 분포, 이갈이 및 하악골융기의 발현 율, 이갈이와 하악골융기의 상관관계를 비교 및 분석하기 위해 chi square test를 사용하였으며, 환자의 평균 연령의 비교는 ttest를 사용하였다.

\section{결 과}

\section{환자의 분포}

본 연구에 참여한 환자들의 분포를 살펴보면 평균 연령은 $\mathrm{TMD}$ 환자군이 37.79 세, 대조군이 46.17세로 나타났다. 성별비 율은 $\mathrm{TMD}$ 환자군에서 남성 $40.8 \%$, 여성 $59.2 \%$, 대조군에서 남 성 $51.5 \%$, 여성 $48.5 \%$ 로 나타났으며, 두 군 간에 유의한 차이 $(p<0.05)$ 를 보였다(Table 1).

\section{이갈이의 유병률}

이갈이의 유병률은 $\mathrm{TMD}$ 환자군에서 $42.9 \%$, 대조군에서 $15.9 \%$ 로 나타났으며, 두 군 간의 유의한 차이 $(p<0.05)$ 를 보였 다(Table 2).

\section{하악골융기의 유병률}

하악골융기의 유병률은 TMD 환자군에서 $22.7 \%$, 대조군에서 $6.7 \%$ 로 나타났으며, 두 군 간의 유의한 차이 $(p<0.05)$ 를 보였다 (Table 3).

Table 1. Demographic characteristics of the subject

\begin{tabular}{lccc}
\hline \multirow{2}{*}{ Characteristic } & \multicolumn{2}{c}{ Group } & p-value \\
\cline { 2 - 3 } & TMD (n=375) & Control (n=433) & \\
\hline Sex & & & $0.002^{\mathrm{a}}$ \\
$\quad$ Male & $153(40.8)$ & $223(51.5)$ & \\
$\quad$ Female & $222(59.2)$ & $210(48.5)$ & \\
Average age (y) & & & \\
$\quad$ Male & $36.75 \pm 19.72$ & $45.01 \pm 19.51$ & $<0.001^{\mathrm{b}}$ \\
Female & $38.50 \pm 18.95$ & $47.40 \pm 20.50$ & $<0.001^{\mathrm{b}}$ \\
Total & $37.79 \pm 19.26$ & $46.17 \pm 20.01$ & $<0.001^{\mathrm{b}}$ \\
\hline
\end{tabular}

Values are presented as number (\%) or mean \pm standard deviation. TMD, temporomandibular disorders.

${ }^{\text {a }}$ Statistical significance was evaluated by the chi-square test $(p<0.05)$.

${ }^{\mathrm{b}}$ Statistical significance was evaluated by the t-test $(p<0.05)$. 
Table 2. Difference in the prevalence of bruxism in each group

\begin{tabular}{ccccc}
\hline \multirow{2}{*}{ Bruxism } & \multicolumn{2}{c}{ Group } & \multirow{2}{\text{Total}}{$n$} & p-value \\
\cline { 2 - 3 } & $\begin{array}{c}\text { TMD } \\
(\mathbf{n}=\mathbf{3 7 5})\end{array}$ & $\begin{array}{c}\text { Control } \\
(\mathbf{n}=\mathbf{4 3 3})\end{array}$ & $(\mathbf{n = 8 0 8 )}$ & \\
\hline Yes & $161(42.9)$ & $69(15.9)$ & $230(28.5)$ & $<0.001^{\mathrm{a}}$ \\
No & $214(57.1)$ & $364(84.1)$ & $578(71.5)$ & \\
\hline
\end{tabular}

Values are presented as number (\%).

TMD, temporomandibular disorders; Yes, existence; No, none-existence.

${ }^{a}$ Statistical significance was evaluated by the chi-square test $(p<0.05)$.

Table 3. Difference in the prevalence of torus mandibularis in each group

\begin{tabular}{ccccc}
\hline \multirow{2}{*}{$\begin{array}{c}\text { Torus } \\
\text { mandibularis }\end{array}$} & $\begin{array}{c}\text { TMD } \\
(\mathbf{n}=\mathbf{3 7 5})\end{array}$ & $\begin{array}{c}\text { Control } \\
(\mathbf{n}=\mathbf{4 3 3})\end{array}$ & $\begin{array}{c}\text { Total } \\
(\mathbf{n}=\mathbf{8 0 8})\end{array}$ & $\boldsymbol{p}$-value \\
\hline Yes & $85(22.7)$ & $29(6.7)$ & $114(14.1)$ & $<0.001^{\mathrm{a}}$ \\
No & $290(77.3)$ & $404(93.3)$ & $694(85.9)$ & \\
\hline
\end{tabular}

Values are presented as number (\%).

$\mathrm{TMD}$, temporomandibular disorders; Yes, existence; No, none-existence.

${ }^{a}$ Statistical significance was evaluated by the chi-square test $(p<0.05)$.

\section{이갈이와 하악골융기 유병률의 상관관계}

$\mathrm{TMD}$ 환자군과 대조군에서 이갈이와 하악골융기 유병률의 상관관계를 비교한 결과 두 군에서 유의한 차이를 보이지 않았 다(Table 4).

\section{고 찰}

$\mathrm{TMD}$ 는 턱관절 및 저작근 부위에 통증과 기능장애를 나타내 는데, 일반적으로 10-20대에 주로 발병하여 연령 증가에 따라 유병률이 증가한다. 또한 남성보다 여성에서 호발한다고 국내 및 국외에서 보고되고 있다[1,3,9]. 본 연구에서의 평균 연령은 $\mathrm{TMD}$ 환자군이 대조군에 비해 낮았으며, 성별은 TMD 환자군에 서 여성이 통계적으로 유의하게 많았다. $\mathrm{TMD}$ 는 여성에서 호발 한다는 연구들과 같은 결과를 나타냈다(Table 1).

이갈이는 TMD 환자에서 흔히 발견되는 기여 요인으로, 유병 률은 연구보고마다 매우 차이가 크다[10]. 원인은 정확하게 알 려져 있지 않지만 교합간섭(occlusal interference), 정서적·육 체적 스트레스, 수면장애, 유전적 소인, 중추신경계의 장애 등 다양한 원인이 중첩되어 발생되는 것으로 여겨지고 있다[2-4]. 이갈이는 주간과 야간에 나타나는데, 구강안면 부위에 부담이
Table 4. Comparison of prevalence of bruxism and torus mandibularis in each group

\begin{tabular}{ccccc}
\hline \multirow{2}{*}{ Group } & \multicolumn{3}{c}{ Torus mandibularis } & p-value \\
\cline { 2 - 4 } & \multicolumn{1}{c}{ Yes } & No & Total & \\
\hline TMD & & & & 0.263 \\
Bruxism & & & & \\
Yes & $32(19.9)$ & $129(80.1)$ & $161(100)$ & \\
No & $53(24.8)$ & $161(75.2)$ & $214(100)$ & \\
Total & $85(22.7)$ & $290(77.3)$ & $375(100)$ & \\
Control & & & & 0.393 \\
Bruxism & & & & \\
Yes & $3(4.3)$ & $66(95.7)$ & $69(100)$ & \\
No & $26(7.1)$ & $338(92.9)$ & $364(100)$ & \\
Total & $29(6.7)$ & $404(93.3)$ & $433(100)$ & \\
\hline
\end{tabular}

Values are presented as number (\%).

TMD, temporomandibular disorders; Yes, existence; No, none-existence.

되는 강도의 힘을 가하고 때로는 생리적 내성을 넘어가는 강도 의 근육 과활성(muscle hyperactivity)을 나타냄으로써 TMD의 증상을 유발하거나 악화시킬 수 있다[2].

Sierwald 등[11]과 Reissmann 등[12]은 주간과 야간에 이 갈이를 할 때 $\mathrm{TMD}$ 와 관련된 통증이 더 증가한다고 하였고, Blanco Aguilera 등[13]도 야간의 이갈이는 60세 이하 여성에 서 통증성 $\mathrm{TMD}$ 증상 및 만성통증의 발생과 연관성이 있다고 하 였다. 이 연구에서도 대조군에 비해 TMD 환자군에서 이갈이가 유의하게 많아 이갈이가 TMD의 발생과 연관되어 있음을 알 수 있었다(Table 2).

하악골융기는 대부분 하악 견치와 후방 대구치 사이에 나타 나는 골 융기이다. 기존 연구에 의하면 20-40세 사이에 주로 발 생하고 대부분 양측으로 나타난다[14]. 그리고 성별 차이는 일 정하지 않지만 하악골융기는 구개융기(torus palatinus)에 비해 남성에서 주로 나타난다[1,14,15]. 원인은 명확하지 않지만 식 이습관, 칼슘의 과다섭취, 다양한 치과적 요소(dental factors), 약물(medication), 의학적 상태(medical conditions)와 같은 환경적 요인들이 하악골융기의 형성에 관여된다고 보고되었고 [14,16], 쌍둥이(twins)를 대상으로 한 연구에서는 유전적인 요 인과 치아를 가는 행위(teeth grinding)가 연관될 수 있다고 하 였다[7].

Clifford 등[17]은 하악골융기의 발생은 이악물기와 치아를 가는 행위와 관련이 있으며, TMD 환자에서 좀 더 일반적으로 나타난다고 하였다. 이 연구에서도 하악골융기는 대조군에 비해 $\mathrm{TMD}$ 환자군에서 더 높게 나타나 Clifford 등[17]의 연구 결과와 일치하였으며, 하악골융기와 TMD는 관련성이 있음을 알 수 있 었다(Table 3). 
하악골융기는 이악물기와 치아를 가는 행위와 같은 이상기능 활동과 연관성이 높으며[17,18], 치아의 마모, 교합력(occlusal force)과도 관련된다고 보고되고 있다[19-21]. 즉, 이악물기와 치아를 가는 행위와 같은 형태로 나타나는 이갈이는 근육의 과 활성과 관련된 과도한 교합력으로 $\mathrm{TMD}$ 의 원인과 하악골융기 의 발생과 연관되어 질 수 있다.

Sirirungrojying와 Kerdpon의 연구[8]에서도 TMD 환자들이 더 높은 이상기능 활동과 하악골융기의 유병률을 보였으며, 이 갈이와 같은 행동의 과도한 힘의 결과가 하악에 스트레스를 가 해 하악골융기의 발생과 $\mathrm{TMD}$ 의 원인이 될 수 있다고 하였다. 하지만 이 연구에서는 이갈이와 하악골융기의 발현율의 상관관 계에 통계적인 유의성은 없어 Bertazzo-Silveira 등[21]의 연구 와 유사하였고, 이갈이와 하악골융기와의 관련성은 입증하기 어려웠다(Table 4). 이러한 결과는 TMD와 하악골융기의 원인 이 다양하기 때문이라고 생각하고, 향후 좀 더 많은 샘플로 장기 간의 추적조사가 필요하다고 본다.

이 연구는 TMD 환자에서 이갈이와 하악골융기의 상관관계 가 있는지를 알아보기 위해 TMD 환자군과 대조군에서 이갈이 와 하악골융기의 유병률을 조사하였다. 이갈이와 하악골융기의 유병률은 대조군보다 TMD 환자군에서 더 높게 나타났다. 이갈 이와 하악골융기의 상관관계는 없었지만, 이갈이와 하악골융기 가 TMD의 발생을 증가시킬 수 있는 지표가 될 수 있음을 알 수 있었다.

\section{ACKNOWLEDGEMENTS}

This study was supported by research fund from Chosun University, 2017.

\section{CONFLICTS OF INTEREST}

The authors declare that they have no competing interests.

\section{ORCID}

\author{
Chan-Young Cheon \\ https://orcid.org/0000-0002-8709-6409 \\ A-Hyang Yoon \\ https://orcid.org/0000-0002-4588-0692 \\ Jong-Mo Ahn \\ https://orcid.org/0000-0002-3615-3688
}

\section{REFERENCES}

1. Kim JH, Ryu JW, Ahn JM. Relationship of Korean teenagers with temporomandibular disorders and sleeping hours. Oral Biol Res 2015;39:47-54.

2. Okeson JP. Management of temporomandibular disorders and occlusion. 5th ed. St.Louise: Mobsy; 2003;141-176.

3. Ok SM, Kim CY, Jeong SH, Ahn YW, Ko MY. Comparative analysis; the patterns of temporomandibular disorder among adolescents. J Oral Med Pain 2012;37:47-59. doi: 10.14476/jomp.2012.37.1.047.

4. Firmani M, Reyes M, Becerra N, Flores G, Weitzman M, Espinosa P. Sleep bruxism in children and adolescents. Rev Chil Pediatr 2015;86:373-379. doi: 10.1016/ j.rchipe.2015.05.001.

5. Singh GD. On the etiology and significance of palatal and mandibular tori. Cranio 2010;28:213-215. doi: 10.1179/ crn.2010.030.

6. Rodríguez-Vázquez JF, Sakiyama K, Verdugo-López S, Amano O, Murakami G, Abe S. Origin of the torus mandibularis: an embryological hypothesis. Clin Anat 2013;26:944-952. doi: 10.1002/ca.22275.

7. Auškalnis A, Rutkūnas V, Bernhardt O, Šidlauskas M, Šalomskienė L, Basevičienè N. Multifactorial etiology of torus mandibularis: study of twins. Stomatologija 2015;17:35-40.

8. Sirirungrojying S, Kerdpon D. Relationship between oral tori and temporomandibular disorders. Int Dent J 1999;49:101-104. doi: 10.1111/j.1875-595X.1999. tb00516.x.

9. Nilsson IM, List T, Drangsholt M. Incidence and temporal patterns of temporomandibular disorder pain among Swedish adolescents. J Orofac Pain 2007;21:127-132.

10. Manfredini D, Winocur E, Guarda-Nardini L, Paesani D, Lobbezoo F. Epidemiology of bruxism in adults: a systematic review of the literature. J Orofac Pain 2013;27:99-110. doi: 10.11607/jop.921.

11. Sierwald I, John MT, Schierz O, Hirsch C, Sagheri D, JostBrinkmann PG, Reissmann DR. Association of temporomandibular disorder pain with awake and sleep bruxism in adults. J Orofac Orthop 2015;76:305-317. doi: 10.1007/ s00056-015-0293-5.

12. Reissmann DR, John MT, Aigner A, Schön G, Sierwald I, Schiffman EL. Interaction between awake and sleep bruxism is associated with increased presence of painful temporomandibular disorder. J Oral Facial Pain Headache 2017;31:299-305. doi: 10.11607/ofph.1885.

13. Blanco Aguilera A, Gonzalez Lopez L, Blanco Aguilera E, De la Hoz Aizpurua JL, Rodriguez Torronteras A, Segura Saint-Gerons R, Blanco Hungría A. Relationship between self-reported sleep bruxism and pain in patients with temporomandibular disorders. J Oral Rehabil 2014;41:564- 
572. doi: 10.1111/joor.12172.

14. Lee KH, Lee JH, Lee HJ. Concurrence of torus mandibularis with multiple buccal exostoses. Arch Plast Surg 2013;40:466-468. doi: 10.5999/aps.2013.40.4.466.

15. Romanos GE, Sarmiento HL, Yunker M, Malmstrom H. Prevalence of torus mandibularis in Rochester, New York, region. N Y State Dent J 2013;79:25-27.

16. Morrison MD, Tamimi F. Oral tori are associated with local mechanical and systemic factors: a case-control study. J Oral Maxillofac Surg 2013;71:14-22. doi: 10.1016/ j.joms.2012.08.005.

17. Clifford T, Lamey PJ, Fartash L. Mandibular tori, migraine and temporomandibular disorders. Br Dent J 1996;180:382-384. doi: 10.1038/sj.bdj.4809094.

18. Kerdpon D, Sirirungrojying S. A clinical study of oral tori in southern Thailand: prevalence and the relation to parafunctional activity. Eur J Oral Sci 1999;107:9-13. doi: 10.1046/j.0909-8836.1999.eos107103.x.

19. Yoshinaka M, Ikebe K, Furuya-Yoshinaka M, Maeda Y. Prevalence of torus mandibularis among a group of elderly Japanese and its relationship with occlusal force. Gerodontology 2014;31:117-122. doi: 10.1111/ger.12017.

20. Jeong CW, Kim KH, Jang HW, Kim HS, Huh JK. The relationship between oral tori and bite force. Cranio 2019;37:246-253. doi: 10.1080/08869634.2017.1418617.

21. Bertazzo-Silveira E, Stuginski-Barbosa J, Porporatti AL, Dick B, Flores-Mir C, Manfredini D, De Luca Canto G. Association between signs and symptoms of bruxism and presence of tori: a systematic review. Clin Oral Investig 2017;21:2789-2799. doi: 10.1007/s00784-017-2081-7. 